\title{
Is Splenectomy Always Effective on Liver Regeneration of Extended Left Lobe Graft After Living Donor Liver Transplantation?
}

\author{
Yasuhiro Maruya, Susumu Eguchi*, Masaaki Hidaka, Akihiko Soyama, Takanobu Hara, \\ Florian Pecquenard, Kantoku Nagakawa, Tomoko Yoshimoto-Haramura, Hajime Matsushima, \\ Takayuki Tanaka, Tomohiko Adachi, Shinichiro Ito, Kengo Kanetaka
}

Department of Surgery, Nagasaki University Graduate School of Biomedical Sciences, 1-7-1 Sakamoto, Nagasaki 852-8501, Japan

\section{ABSTRACT}

Background/Aims: The effect of splenectomy on the liver regeneration of a partial graft after living donor liver transplantation (LDLT) is controversial. In recent years, some studies have shown that platelets have strong effects on promoting liver regeneration, but not with a smallfor-size liver graft. This study aimed to validate the effects of splenectomy on liver regeneration rate after LDLT with extended left lobe graft with the middle hepatic vein.

Methodology: Of 312 LDLT to date, 32 adult patients at Nagasaki University Hospital (Nagasaki, Japan) transplanted with an extended left lobe graft with middle hepatic vein between April 2013 and April 2019 were retrospectively assessed. In our department, the preoperative platelet count indicated for splenectomy is $\leq 50,000 / \mu \mathrm{L}$. Overall, 13 and 19 patients were included in the splenectomy and without splenectomy groups, respectively. We examined the relations hip between splenectomy and liver volume increase, and postoperative platelet count on the 1st, 3rd, 5th, and 7th postoperative day. The liver volume 1 month (1MVol) after LDLT was estimated using a 3D image analysis system.

Results: ROC curve analysis showed the spleen volume threshold for significant volume increase (1MVol/graft weight $\geq 2$ ) was $440 \mathrm{ml}$. With regard to $1 \mathrm{MVol}$, no significant difference was observed between the splenectomy and without splenectomy groups. However, in the splenectomy group, recipients with a large spleen (more than $440 \mathrm{ml}$ ) led to higher liver volume increase than in those with a small spleen. Platelet count significantly increased from postoperative day 14 in the splenectomy group regardless of the size of the spleen.

Conclusions: Simultaneous splenectomy does not always have an effect on liver regeneration in extended left lobe graft LDLT. However, for LDLT recipients with large spleen volume, graft volume increase was affected, probably through vigorous portal venous blood flow but not plateletderived factors.

Key words: liver transplantation, splenectomy, regeneration

\section{INTRODUCTION}

Splenectomy is a well-known procedure in living donor liver transplantation (LDLT) to modulate portal venous flow, improve thrombocytopenia in patients with HCV-related liver cirrhosis, and for immunomodulation in ABO-incompatible cases $(1,2)$. However, the effect of splenectomy on liver volume increase of a

\author{
*Corresponding author: \\ Susumu Eguchi, MD \\ Department of Surgery \\ Nagasaki University Graduate Schoo \\ of Biomedical Sciences, \\ 1-7-1 Sakamoto, Nagasaki 852-8501, \\ Japan \\ Tel: +81-95-819-7316 \\ Fax: +81-95-819-7319 \\ E-mail: sueguchi@nagasaki-u.ac.jp
}


partial graft after LDLT is controversial. Recent reports have indicated improvement in liver regeneration after splenectomy (3), because the spleen has an inhibitory effect on liver regeneration by upregulating TGF- $\beta 1$ and downregulating HGF in the liver (4). We also have previously reported the in of the cytokines and liver-related growth factors in the blood after LDLT and after LDLT donor hepatectomy (5-7).

However, the effect of splenectomy on liver regeneration of a partial graft following LDLT remains unclear. Thus, the effect of splenectomy on liver regeneration of a partial graft after LDLT is controversial. In recent years, some studies have shown that platelets have a strong effect on promoting liver regeneration (8, 9). However, the major impacts of splenectomy are increased susceptibility to postoperative infections, especially overwhelming postsplenectomy sepsis (OPSS) caused by encapsulated bacteria, vascular thrombosis, and postoperative bleeding (10).

Therefore, this study aimed to validate the effects of splenectomy and postoperative platelet count on liver regeneration rate after LDLT. In particular, smaller liver lobe transplantation using an extended left lobe graft was investigated because it has no problem in venous outflow with middle and left hepatic venous drainage from the graft and should have vigorous regenerative capacity as compared to right lobe transplantation.

\section{METHODOLOGY}

Of 312 LDLT to date, 32 adult patients who underwent LDLT with extended left lobe graft at Nagasaki University Hospital (Nagasaki, Japan) between January 2013 and March 2017 were retrospectively assessed. Our selection criteria of graft liver was reported previously (11). Only patients who underwent LDLT with extended left lobe graft were included. As shown in fig. 1, the exclusion criteria were: right lobe graft, no 1 month follow up CT after LDLT, and splenectomy prior to LDLT. Thirty-two cases were analyzed and divided into two groups: with splenectomy $(n=13)$ and without splenectomy $(n=19)$.

In our department, the preoperative platelet count indicated for splenectomy is $\leq 50,000 / \mu \mathrm{L}$. Platelet transfusion was done during and after LDLT on occasion only for bleeding tendency episode but very much limited.

The liver volume 1 month (1MVol) after LDLT and pretransplant spleen volume was measured using a 3D image analysis system (SYNAPSE VINCENT ${ }^{\circledR}$, Fuji Film Medical Co, Tokyo, Japan). Liver regeneration rate was calculated by estimated $1 \mathrm{MVol}$ to actual weight of the graft liver. The relationship between splenectomy and liver volume increase, and postoperative platelet count on the $1 \mathrm{st}$, 3rd, 5th, and 7th postoperative day were examined.

Subgroup analysis for liver volume increase in the splenectomy group based on spleen volume was performed after ROC curve analysis to set the spleen volume threshold for significant volume increase (1MVol/graft weight $\geq 2$ ).

From January 1997 April 2020, 312 LDLTs were performed at Nagasaki University Hospital.

Retrospective series of adult patients

who underwent LDLT from April 2013 to April 2019. $\mathrm{N}=73$

Figure 1 - Flowchart of study design

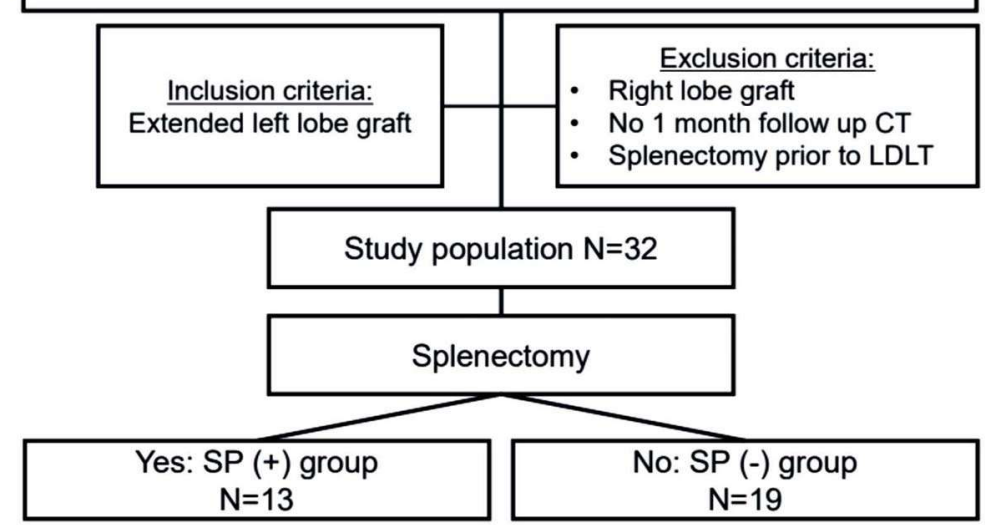




\section{RESULTS}

Table 1 shows the characteristics of our extended left lobe donors. Between the splenectomy group and without splenectomy group, there was no significant difference in age, gender, or body mass index. However, there was a significant difference in ABOincompatibility due to immunological concern previously.

Table 2 shows characteristics of the recipients who received LDLT with extended left lobe graft. There were no statistically significant differences between the groups in age, gender, body mass index, model for liver disease score, Child-Pugh score, and original liver diseases. However, because of its indication, the splenectomy group had lower pretransplant platelet count than that in the without splenectomy group.

Table 3 shows no difference between the groups regarding the surgery, including graft weight and graft weight versus standard liver volume of the recipient calculated from body surface area. Neither primary graft dysfunction nor in-hospital mortality were seen in either group.

In fig. 2, ROC curve analysis showed the spleen volume threshold for significant volume increase (1MVol/graft weight $\geq 2$ ) was $440 \mathrm{ml}$. With regard to $1 \mathrm{MVol}$, no significant difference was observed between the splenectomy and without splenectomy groups (fig. 3). However, regardless of splenectomy status, recipients with a large spleen (more than $440 \mathrm{ml}$ ) led to higher liver volume increase than in those with a small spleen (fig. 4). The platelet count significantly increased

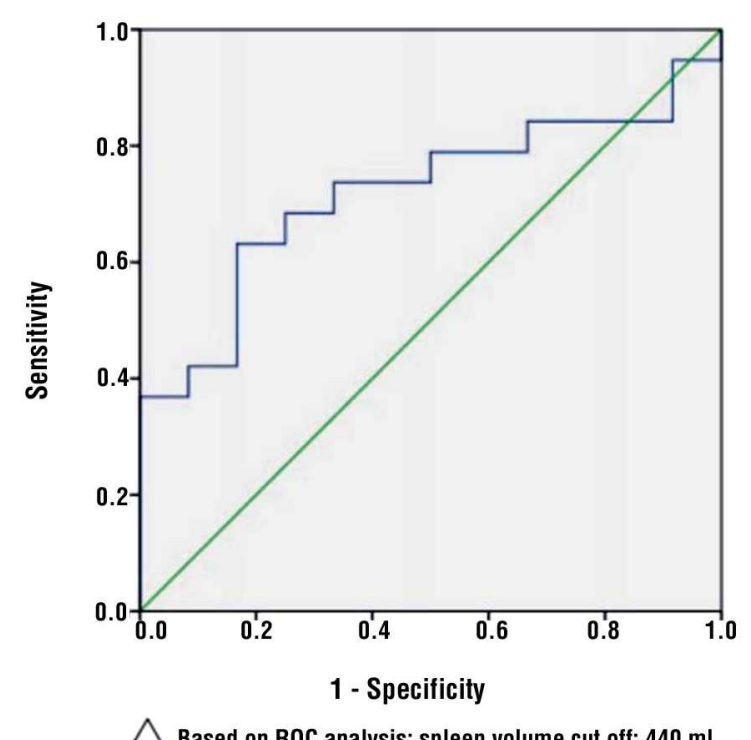

Figure 2 - Receiver operating characteristics curve for spleen size to reflect $100 \%$ volume restoration of the graft at $1 \mathrm{M}$

(1MVol/graft weight $\geq 2$ )
Table 1 - Patients characteristics in extended left lobe donor

\begin{tabular}{lccc}
\hline Variables & $\begin{array}{c}\text { SP } \mathbf{+}) \\
(\mathbf{n = 1 3})\end{array}$ & $\begin{array}{c}\text { SP (-) } \\
(\mathbf{n = 1 9 )}\end{array}$ & $\mathbf{p}$ value \\
\hline Age (year) & $34(23-63)$ & $36(20-60)$ & N.S. \\
\hdashline Sex M/F & $10 / 3$ & $17 / 2$ & N.S. \\
\hdashline BMl (kg/m²) & 23.1 & 22.8 & \\
& $(18.5-27.9)$ & $(16.3-35.1)$ & N.S. \\
\hline ABO blood type: & & & $<\mathbf{0 . 0 5}$ \\
\hline Identical/compatible & $4 / 3$ & $14 / 3$ & \\
\hline Incompatible & 6 & 2 & \\
\hline
\end{tabular}

SP: splenectomy; BMI: body mass index

Table 2 - Recipient characteristics underwent LDLT with extended left lobe graft

\begin{tabular}{|c|c|c|c|}
\hline Recipient & $\begin{array}{c}\mathrm{SP}(+) \\
(n=13)\end{array}$ & $\begin{array}{c}\text { SP }(-) \\
(n=19)\end{array}$ & $\mathrm{p}$ value \\
\hline Age (year) & $59(43-66)$ & $58(24-70)$ & N.S. \\
\hline Sex M/F & $8 / 5$ & $9 / 10$ & N.S. \\
\hline $\mathrm{BMI}\left(\mathrm{kg} / \mathrm{m}^{2}\right)$ & $\begin{array}{c}25.1 \\
(19.5-41.9)\end{array}$ & $\begin{array}{c}23.3 \\
(16.4-33.7)\end{array}$ & N.S. \\
\hline MELD score & $18(8-39)$ & $18(7-33)$ & N.S. \\
\hline Child Pugh score & $11(8-14)$ & $11(7-14)$ & N.S. \\
\hline $\begin{array}{l}\text { Pre-operative platelet } \\
\text { count }\left(\times 10^{3} / \mathrm{LL}\right)\end{array}$ & $\begin{array}{c}4.3 \\
(1.9-6.9) \\
\end{array}$ & $\begin{array}{c}10.3 \\
(4.3-17.2) \\
\end{array}$ & $<0.01$ \\
\hline \multicolumn{4}{|l|}{ Original liver disease: } \\
\hline $\begin{array}{l}\text { C-LC/PBC / B-LC / } \\
\text { ETOH LC / FHF / } \\
\text { NBNC-LC / others }\end{array}$ & $\begin{array}{c}6 / 1 / 1 / \\
3 / 0 / 1 / 1\end{array}$ & $\begin{array}{c}3 / 3 / 2 / \\
4 / 1 / 2 / 4\end{array}$ & N.S. \\
\hline
\end{tabular}

SP: splenectomy, BMI: body mass index, MELD: model for end-stage liver disease; C-LC: liver cirrhosis due to hepatitis C virus infection, B-LC: liver cirrhosis due to hepatitis; B virus infection, ETOH-LC: C-LC: liver cirrhosis due to ethanol, FHF: fulminant hepatic failure, NBNC-LC: liver cirrhosis without non B-non C hepatitis virus infection

Table 3 - LDLT characteristics in the recipients with extended left lobe graft

\begin{tabular}{|c|c|c|c|}
\hline Variables & $\begin{array}{c}S P(+) \\
(n=13)\end{array}$ & $\begin{array}{c}S P(-) \\
(n=19)\end{array}$ & $p$ value \\
\hline $\begin{array}{l}\text { Operation duration } \\
\text { (min) }\end{array}$ & $\begin{array}{c}805 \\
(677-1031)\end{array}$ & $\begin{array}{c}744 \\
(586-908)\end{array}$ & N.S. \\
\hline $\begin{array}{l}\text { Warm ischemic time } \\
(\min )\end{array}$ & $\begin{array}{c}45 \\
(34-72)\end{array}$ & $\begin{array}{c}44 \\
(35-60)\end{array}$ & N.S. \\
\hline $\begin{array}{l}\text { Cold ischemic time } \\
\text { (min) }\end{array}$ & $\begin{array}{c}79 \\
(55-130)\end{array}$ & $\begin{array}{c}74 \\
(42-108)\end{array}$ & N.S. \\
\hline Graft weight $(\mathrm{g})$ & $\begin{array}{c}437 \\
(340-557)\end{array}$ & $\begin{array}{c}414 \\
(316-625)\end{array}$ & N.S. \\
\hline GV/ SLV (\%) & $\begin{array}{c}39.4 \\
(22.7-47.9)\end{array}$ & $\begin{array}{c}39.1 \\
(30.9-56.9)\end{array}$ & N.S. \\
\hline GW/SLV (\%) & $\begin{array}{c}33.1 \\
(25.6-44.2)\end{array}$ & $\begin{array}{c}34.7 \\
(26.2-60.9)\end{array}$ & N.S. \\
\hline Blood loss (g) & $\begin{array}{c}8,720 \\
(2,930-30,500)\end{array}$ & $\begin{array}{c}5,550 \\
(2,050-36,900)\end{array}$ & N.S. \\
\hline $\begin{array}{l}\text { Primary graft } \\
\text { dysfunction/inhospital } \\
\text { death }\end{array}$ & $0 / 0$ & $0 / 0$ & N.S. \\
\hline
\end{tabular}




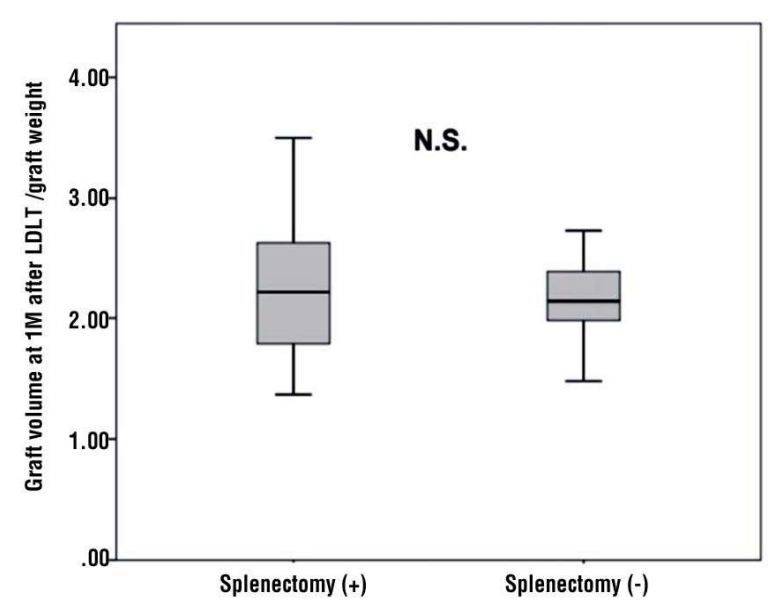

Figure 3 - Liver volume increase at 1 month after extended left lobe graft LDLT

from postoperative day 14 in the splenectomy group regardless of the size of the spleen (fig. 5).

\section{DISCUSSION}

Because of a shortage of brain-dead donors, partial liver transplantation from living donors has gained worldwide popularity (12). In contrast with whole liver transplantation, partial liver allograft allows the graft to regenerate to adapt to the recipient environment.

For this reason, partial liver transplantation offers a unique opportunity to investigate the yet-unresolved mechanisms of liver regeneration (13-15).

We previously reported the changes in the cytokines and liver-related growth factors in the blood after living donor liver transplantation and in donors (5, 7)a. During liver regeneration in humans, many related factors are released through autocrine and paracrine as well as exocrine signaling through the stimulation of volume reduction, hepatic flow/pressure change, space loss, and nerve disturbance to the grafted partial liver. Among those, some in vivo experiments in small animals have indicated improvement in liver regeneration after splenectomy because the spleen has an inhibitory effect on liver regeneration by upregulating TGF- $\beta 1$ and downregulating HGF in the liver (16).

Splenectomy is a well-known procedure in LDLT to improve thrombocytopenia in patients with HCVrelated liver cirrhosis and for immunomodulation in ABO-incompatible cases (1). Also, splenectomy can be used to reduce the portal venous flow in the case of small-for-size graft LDLT (2). However, the mechanisms involvement of the spleen in partial liver regeneration has not yet been elucidated well yet. Also, splenectomy itself has been reported to associate with several complications, such as portal vein thrombosis (17-20).

In this study, the evaluation of post-transplant liver graft volume showed that simultaneous splenectomy itself does not always affect liver regeneration rate after LDLT. However, in the splenectomy group, a correlation was found between preoperative size of the spleen and liver regeneration rate, while the platelet count itself after LDLT did not show a correlation with liver volume restoration. Of course, pleatelet count was increased in the splenectomy group, but there was no significant differe nce in the preoperative size of the spleen.

Recently, the impact of imbalanced graft-to-spleen

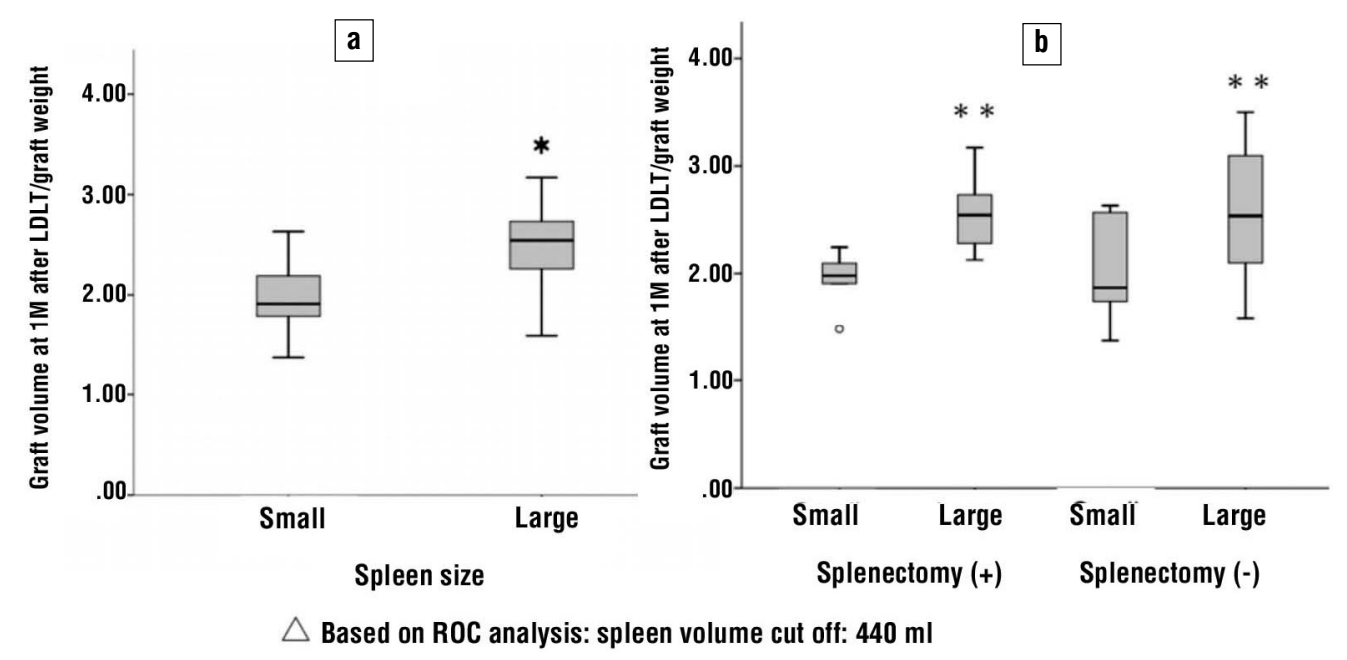

Figure 4 - Liver volume increase in the splenectomy group regarding spleen size (a) and comparison with non-splenectomy group (b) 


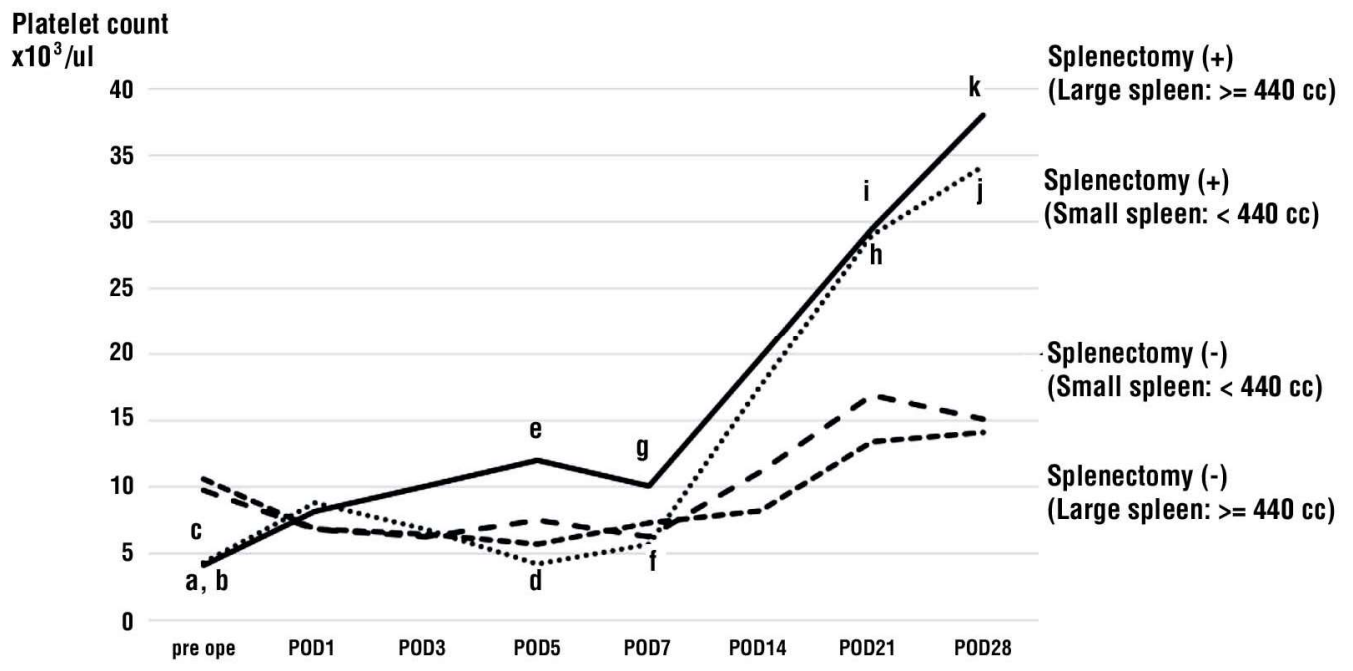

Figure 5 - Platelet count after extended left graft LDLT according to spleen size and splenectomy. a: $p<0.05$ vs splenectomy (-) small, $b: p<0.01$ vs splenectomy $(-)$ large, $c: p<0.01$ vs splenectomy $(-)$ large, $d: p<0.01$ vs splenectomy (+) large, e: $p<0.05$ vs splenectomy (-) large, $f: p<0.01$ vs splenectomy $(+), g: p<0.01$ vs splenectomy (-) small, $h: p<0.05$ vs splenectomy (-) large, i: $p<0.05$ vs splenectomy (-) large, j: $p<0.05$ vs splenectomy (-) large, $k: p<0.05$ vs splenectomy (-) large

volume ratio on graft survival was reported by Yao et al (3). In the report, a combination of small graft and large spleen gave the worst outcome, as well as increased age of the donor. A graft volume to body weight ratio of 0.7 was used as the cutoff value for small for size graft without mentioning left or right lobe graft in the analysis. In our study, an extended left lobe graft, which is deemed to be a small graft between $0.6-0.8 \%$, was investigated so that our conclusions could be compared to those reported by Yao, but all venous drainage was insured in the left lobe graft as compared to a right lobe graft $(21,22)$. Therefore, our results provide clearer information when the extended left lobe graft with middle hepatic vein is to be selected.

There are some limitations to this retrospective study. 1 . The number of patients is limited in this study. 2. Portal venous pressure during and after LDLT was not measured, which make it impossible to presume its effect on liver regeneration. 3. Liver-related cytokines such as hepatocyte growth factor, transforming growth factor alpha and beta, and others were not measured, which were all related to liver regeneration in small aminmal studies and some our previous reports.

\section{CONCLUSION}

In conclusion, according to this evaluation of postoperative liver volume increase, simultaneous splenectomy does not always have an effect on liver regenera- tion in extended left lobe graft LDLT. However, for LDLT recipients with large spleen volume, graft volume increase was affected, probably through vigorous portal venous blood flow but not plateletderived factors.

\section{Ethical approval}

All procedures performed in studies involving human participants were in accordance with the ethical standards of the institutional and/or national research committee and with the 1964 Helsinki Declaration and its later amendments or comparable ethical standards.

\section{Disclosure}

The authors have no financial conflicts of interest to disclose concerning this study.

\section{REFERENCES}

1. Yoshizumi T, Mori M. Portal flow modulation in living donor liver transplantation: review with a focus on splenectomy. Surg Today. 2020;50(1):21-29.

2. Egawa H, Ohmori K, Haga H, Tsuji H, Yurugi K, Miyagawa-Hayashino A, et al. B-cell surface marker analysis for improvement of rituximab prophylaxis in $\mathrm{ABO}$-incompatible adult living donor liver transplantation. Liver Transpl. 2007;13(4):579-588.

3. Yao S, Kaido T, Yagi S, Uozumi R, Iwamura S, Miyachi Y, et al. Impact of imbalanced graftto-spleen volume ratio on outcomes following living donor liver transplantation in an era when simultaneous splenectomy is not typically indicated. Am J Transplant. 2019;19(10):2783-2794 
4. Kim J, Kim CJ, Ko IG, Joo SH, Ahn HJ. Splenectomy affects the balance between hepatic growth factor and transforming growth factor- $\beta$ and its effect on liver regeneration is dependent on the amount of liver resection in rats. J Korean Surg Soc. 2012; 82(4):238-245.

5. Soyama A, Eguchi S, Hamada T, Takatsuki M, Kamohara Y, Kawashita $Y$, et al. The impact of hepatic denervation on the accumulation of hepatic progenitor cells during liver regeneration in rats. Hepatogastroenterology. 2012;59(117):1577-1579.

6. Eguchi S, Okudaira S, Azuma T, Ohno Y, Fujioka H, Furui J, et al. Changes in liver regenerative factors in a case of living-related liver transplantation. Clin Transplant. 1999;13(6):536-544.

7. Eguchi S, Yanaga K, Okudaira S, Sugiyama N, Miyamoto S, Furui J, et al. Changes in serum levels of hepatocyte growth factor in patients undergoing adult-to-adult livingdonor liver transplantation. Transplantation. 2003;76(12):1769-1770.

8. Chen HL, Chen CL, Huang TL, Chen TY, Tsang LLC, Ou HY, et al. Regeneration rate of left liver grafts in adult living donor liver transplant. Transplant Proc. 2010;42(3):699-700.

9. Cheng YF, Huang TL, Chen TY, Tsang L LC, Ou HY, Yu CY, et al. Liver graft regeneration in right lobe adult living donor liver transplantation. Am J Transplant. 2009;9(6):1382-1388.

10. Ito K, Akamatsu N, Ichida A, Ito D, Kaneko J, Arita J, et al. Splenectomy is not indicated in living donor liver transplantation. Liver Transpl. 2016;22(11):1526-1535.

11. Imamura H, Hidaka M, Soyama A, Kitasato A, Adachi T, Ono S, et al A Donor AgeBased and Graft Volume-Based Analysis for Living Donor Liver Transplantation in Elderly Recipients. Transplant Direct. 2017;3(7):e168.

12. Umeshita K, Eguchi S, Egawa H, Haga H, Kasahara M, Kokudo N, et al. Liver transplantation in Japan: Registry by the Japanese Liver Transplantation Society. Hepatol Res. 2019;49(9):964-980.

13. Eguchi S, Yanaga K, Sugiyama N, Okudaira S, Furui J, Kanematsu T. Relationship between portal venous flow and liver regeneration in patients after living donor right-lobe liver transplantation. Liver Transpl. 2003;9(6):547-551.
14. Pravisani R, Soyama A, Takatsuki M, Hidaka M, Adachi T, Ono S, et al. Relationship Between Venous Drainage Patterns and Regeneration of Segments 5 and 8 in Right Lobe Grafts in Adult Living-Donor Liver Transplant Recipients. Exp Clin Transplant. 2019;17(4):529-535.

15. Pravisani R, Soyama A, Ono S, Baccarani U, Isola M, Takatsuki M, et al. Is there any correlation between liver graft regeneration and recipient's pretransplant skeletal muscle mass?-a study in extended left lobe graft living-donor liver transplantation. Hepatobiliary Surg Nutr. 2020;9(2):183-194.

16. Takahashi K, Nagai S, Safwan M, Liang C, Ohkohchi N. Thrombocytopenia after liver transplantation: Should we care? World J Gastroenterol. 2018;24(13):1386-1397.

17. Ushitora Y, Tashiro H, Takahashi S, Amano H, Oshita A, Kobayashi T, et al. Splenectomy in chronic hepatic disorders: portal vein thrombosis and improvement of liver function. Dig Surg. 2011;28(1):9-14.

18. Lv X, Yang F, Guo X, Yang T, Zhou T, Dong X, et al. Hypersplenism is correlated with increased risk of hepatocellular carcinoma in patients with post-hepatitis cirrhosis [published correction appears in Tumour Biol. 2016 Jul;37(7):9989]. Tumour Biol. 2016;37(7):8889-8900.

19. Nomura Y, Kage M, Ogata T, Kondou R, Kinoshita H, Ohshima K, et al. Influence of splenectomy in patients with liver cirrhosis and hypersplenism. Hepatol Res. 2014;44(10):E100-E109.

20. Liu X, Chen Z, Yu M, Zhou W, Zhi X, Li T. Safety of Simultaneous Hepatectomy and Splenectomy in the Treatment of Hepatocellular Carcinoma Complicated with Hypersplenism: A Meta-analysis. Gastroenterol Res Pract. 2019;2019:9065845.

21. Chen TY, Chen CL, Huang TL, Tsang L LC, Ou HY, Yu CY, et al. Does hepatic graft weight affect the reduction of spleen size after living donor liver transplantation? Transplant Proc. 2010;42(3): 882-883.

22. Liu G, Xie C, Fang Y, Qian K, Liu Q, Liu G, et al. Splenectomy after partial hepatectomy accelerates liver regeneration in mice by promoting tight junction formation via polarity protein Par 3-aPKC. Life Sci. 2018;192:91-98. 